\title{
The Implementation of Business Intelligence System in University with OLAP Method
}

\author{
Lita A. Ndoloe ${ }^{1}$, Jemsrado Sine ${ }^{1}$, Arsono Subiontoko ${ }^{1}$ \\ \{litandolu83@gmail.com, jemsrado.shine@gmail.com, soni582002@yahoo.com\} \\ Politeknik Negeri Kupang ${ }^{1}$
}

\begin{abstract}
Abstarct. Business intelligence system of Universities started with stages of integrating data, analyzing data, making reports and creating web portals then integrating the reports by using the web portal. Data analysis would be processed by using Online Analytical Processing (OLAP), Key Performance Indicators (KPI) and data mining to extract the information from data stored in the data warehouse. The results of the data analysis process will be represented in the form of statistical reports and dashboards, and then it can be used to support academic decision-making. This study aimed to design a business intelligence system web based university with OLAP methods that can be used in academic decision making at Kupang State Polytechnic. This research produces a university website business intelligence system that can be accessed through an online browser.
\end{abstract}

KeyWord: Business Intelligence, Data warehouse,OLAP, KPI, Data mining

\section{Background}

Business Intelligence (BI) has a very important role in decision making to help managers and leaders of Universities (PT) to improve the performance of Universities [1]. BI is an important element in intellectual capital management. Intellectual capital as Universities assets becomes important and strategic to achieve competitive advantage in accordance with the vision, mission and goals of Universities. BI application aims to collect data, store data, analyze data and provide an access to data, so it can help management in making decisions accurately by doing various Universities activities to prepare universities strategic planning in the future. The role of BI in Universities management is to optimize the performance of academic business processes by encouraging the effective and efficient use of intellectual capital [2]. The universities performance measurement methods are needed as a basic for strategy development, action plans, improvement programs and activities continuously.It is also used to measure the performance, monitor the actual situation and to plan performance improvements in the future [3].

The advantages of implementing BI solutions with the Online Analytical Processing (OLAP) approach in academic and student information systems are collecting data, storing data, analyzing data and providing access to data so it can help users in making decisions accurately and quickly by doing various OLAP activities including; roll up, drill down, filtering, aggregation, pivoting,slicing and dicing [4]. 
This research aims to implement a business intelligence system to support the Universities management in a more competitive direction through the planning system, measuring and improving performance based on capital intellectual management. Business Intelligence System (SBI) is designed web-based with OLAP method [5]. The use of the key performance indicators universities is designed to meet quality standards nationally,internationally and globally. As input data on Business Intelligence System (SBI) comes from various transactional data for example,lecturers, administrative staff, students, including aspects of financial administration. SBI in the Academic information system is formulated in academic key performance indicators (IKK) Universities that become one of the important benchmarks to achieve Universities success rates.

The aplication of Business intelligence (BI) solutions with OLAP in academic and student information systems can be used as a solution in considering the decision making process in managing the universities and also as a solution in improving academic performance to achieve academic excellence as well as being able to assist makinguniversities' strategic planning in the future [6]. Because BI solutions can be used in considering the decision making process at universities as an important part of large business management for the education in Indonesia, this is due to factors that affect performance and optimization in the management of universities as well as business processes in profit companies in general.

The purpose of this research is to develop an application for universities using websitebased OLAP method that will provide useful information for universities management for decision making in the academic system [7].

With the website based Business Intelligence System using OLAP method,it can provide important information about the academic process that occurs or takes place in universities so it can be used by the leaders in making decisions for the improvement of the academic system towards better universities performance [8].

\section{Research methods}

The methods used in this research consisted of the following steps:

1. This research uses primary data in the form of report documents and academic and student database files

2. Conducting a literature study of various references relating to theresearch . Topics studied include Bussines Intelligence,OLAP method, data warehouse, Waterfall Models

3. Designing business intelligence system application at the universities withOLAP method

4. Testing business intelligence system application at the universities with the OLAP method. 
The application procedure is shown in Figure 1.

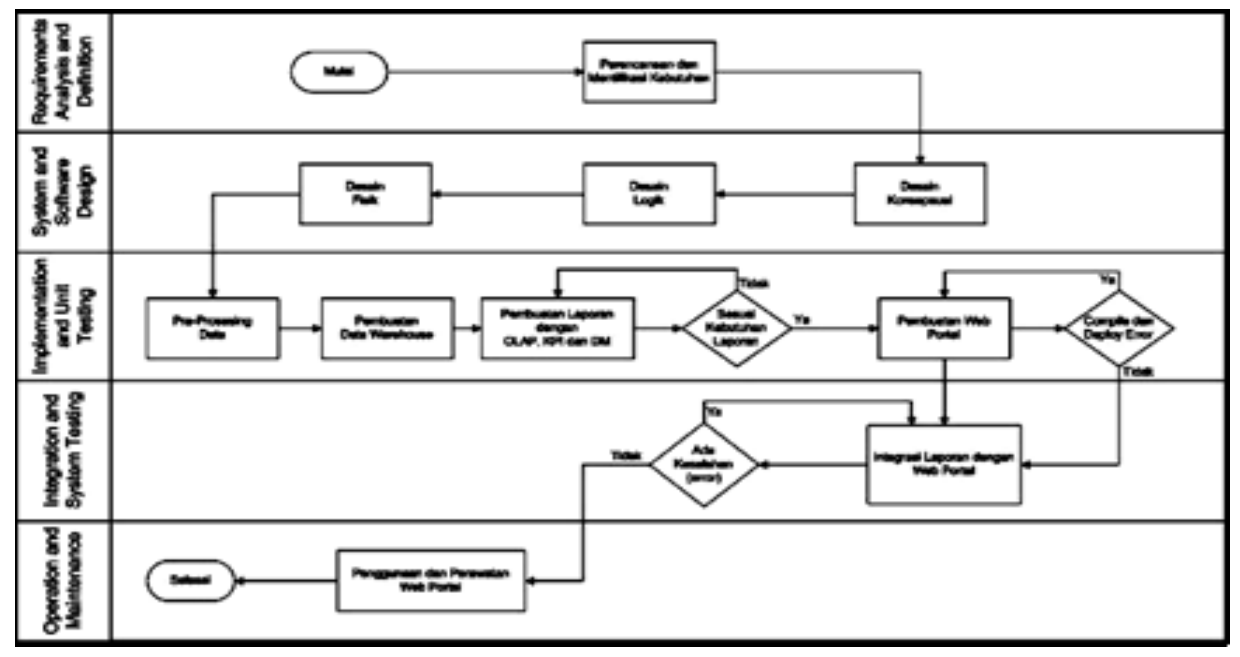

Figure 1. Research Procedures

Figure 1 shows the research procedures about the design of Business Intelligence system at the Universities

Following is an explanation of the components in Business Intelligence system at the universities Figure 1 can be explained as follows:

1. Requirements Analysis and Definition

The Planning and Identification Process is the stage where we do the planning and identifying data source, data warehouse and the process of Business Intelligence system and the website that will be built according to the user's wishes [9]. University Business Intelligence system website users are divided into two parts namely: University Business Intelligence system website users are divided into two parts namely:

a. The user consists of the Director, Deputy Directors, where the user can only interact directly interface

b. Administrator, who has the same access as the user and has access to the location of database used.

2. System and Software Design

The Conceptual Design Process in this stage is doing the process of data warehouse scheme design. This stage is also carried out the analysis phase measure and what dimensions will be used. The Logic Design Process in this stage are planning and making a database by making data relations and determine the relationship of one attribute with another attribute with the UML method [10]. This stage also analyzes database storage and database settings. Physical Design Process describes the cube data that is ready to be used in the data warehouse. This stage is also said to be the stage of the scheme that has been obtained implement it in the data warehouse to be built. Early stages before heading to the process of making a data warehouse is done by collecting data and analyzing values and attributes to get the right attributes to create data warehouse, after selecting and knowing its attribute, 
then proceed to Pre-processing data stages. Data Pre-Processing Process consists of processes before entering into data warehouse creation, data must be processed first.

The following data pre-processing stages are:

a. Data integration namely integration which is done by combining the interesting attributes from the table being analyzed;

b. Data reduction is done together with the process of data integration, i.e.removing unattractive attributes from the analyzed table;

c. Data cleaning.It is performed on the attributes that has inconsistent writing;

d. Data transformation is the process of uniforming attribute names, generalizing, aggregating,and the construction of attributes or dimensions, the end of this transformation stage is the formation of a data warehouse.

Integration of Reports and Web Portal is done by merging or integration between Statistical reports and dashboard reports with the Business Intelligence system web portal then checking for errors. If an error occurs, a repair can be made to the sytem.

\section{Result and Discussion}

\subsection{The framework of Universities Business Intelligence System}

The university's Business Intelligence system framework is description about the components that become foundation and also the component layout in building a Business Intelligence system university. Figure 2 is the basic framework of university Business Intelligence system that has become result.

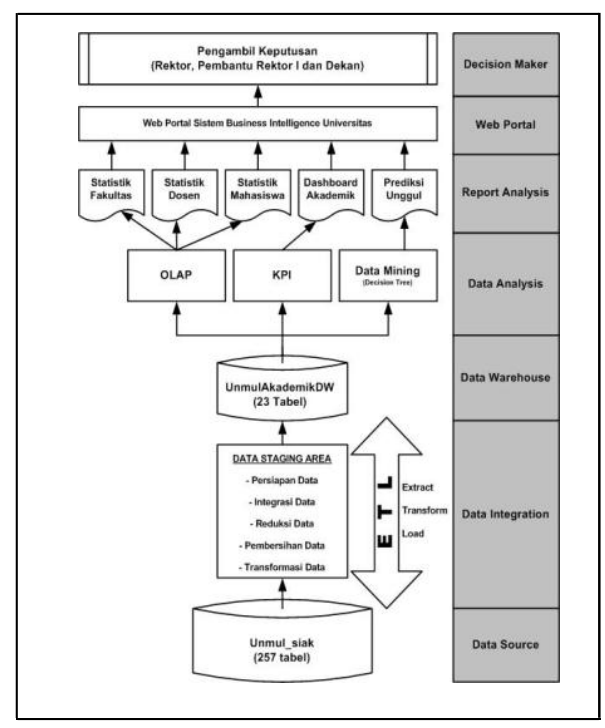

Figure 2. Basic Framework of the system Business Intelligence in University 
The following component explanation on the universities business intelligence system:

\section{Data Source}

Data Source comes from academic and student databases of Kupang State Polytechnic University which is called Poltek_Siak. In the database there are 5 tables. Furthermore, the tables that will be used as source data are selected in accordance with the needs relating to the data of lecturers, data of incoming students and graduate student's data, study program accreditation data from 2017- until 2020

\section{Data Integration}

It is a process of integrating data from the Poltek_Siak database (data source), then streams the selected data to the PoltekAkademikWW database (datawarehouse) using DbPoltekSiak database (data staging) usingMicrosoft SQL Server Integration Service software.

\section{Data Warehouse}

The data warehouse used is a relational database created with Microsoft SQL Server 2008 R2 software and database are named PoltekAkademikWD which consists of 3 fact tables and 2 dimension tables, so that all total table are 5 tables.

\section{Data Analysis}

The data analysis process uses Microsoft SQL Server Analysis software Services which are technology components for OLAP and data mining. OLAP process done in SQL Server Management Studio in the form of viewing data, making multidimensional expressions, data mining extensions, XML for Analysis and also define roles forOLAP security access.

\section{Report Analysis}

Report Analysis is a report made as a support in making decision, because the report format is in the form of statistical analysis and dashboard. In research this report was created using Microsoft SQL Server software Reporting Services, because reports can be made in tabular, graphic and indicator formsfrom OLAP data sources that are on the analysis server. Reports made in the form of statisticsMajors, lecturer statistics, student statistics and academic dashboards as well as superior predictions. The results of the report are published or deployed to the report server.

\subsection{Academic KPI}

The predicate of a key performance indicator or academic KPI is based on the status categoryaccreditation, the category of lecturer holds a doctorate, and the category of students graduating with cum laude.

Table 2 Accreditation Status Categories

\begin{tabular}{|l|l|l|}
\hline Predicate & KPI Requirements & Color indicator \\
\hline superior & $\begin{array}{l}\text { Average Accreditation Value } \\
\text { Entire Program Studies range } \\
\text { from 3.50 up to 4.00 }\end{array}$ & Green \\
\hline good & $\begin{array}{l}\text { Average Accreditation Value } \\
\text { Entire Program } \\
\text { Studies range from 3.00 }\end{array}$ & Yellow \\
\hline
\end{tabular}




\begin{tabular}{|l|l|l|}
\hline & up to 3.49 & \\
\hline Developing & Average Accreditation Value & Blue \\
& Entire Program & \\
& Studies range from 2.50 & \\
up to 2.99 & \\
\hline Growing & $\begin{array}{l}\text { Average Accreditation Value } \\
\text { Entire Program }\end{array}$ & Red \\
& $\begin{array}{l}\text { Studies range from 2.00 } \\
\text { up to 2.49 }\end{array}$ \\
\hline
\end{tabular}

\subsection{Web Portal Business Intelligence university}

This research produced a prototype web portal Business Intelligence System Universities that are used as support for academic decision making for university leaders. Figure 3 is the page display or main page for users or users on the web Portal Business Intelligence system university.

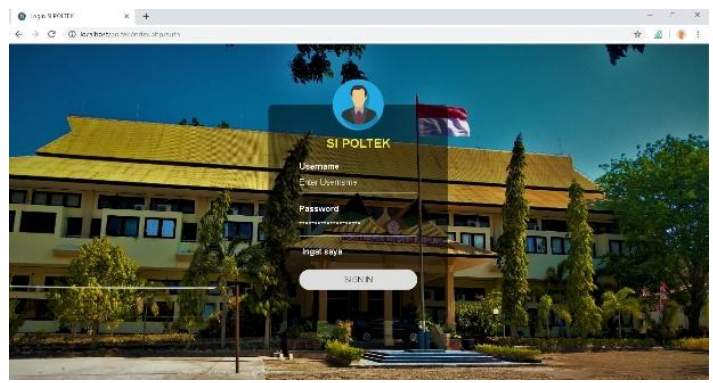

Figure 3. User Interface

Figure 3 is the interface of the statistical report of the number of lecturers according to department and gender based on the functional position of lecturers in graph and table report format, where this report has a function to inform the number, sub-total and number of lecturers who have functional positions according to gender type in each department

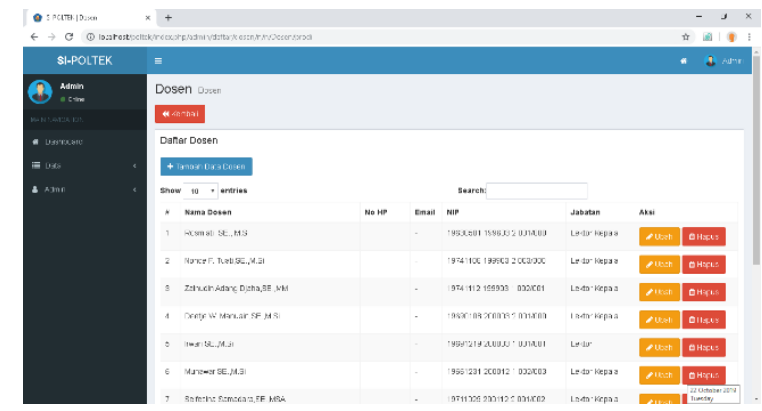

Figure 4. Dashboard lecturer doctoral degree status

Figure 4 is an academic dashboard of study program performance based comparison or ratio of the number of lecturers with functional positions with all lecturers on study programs or all lecturers in the Department according to the Department. This dashboard report has a function 
to inform the number of all lecturers in the Department, lecturer ratio performance indicators, predicate performance and decision recommendations in each Department.

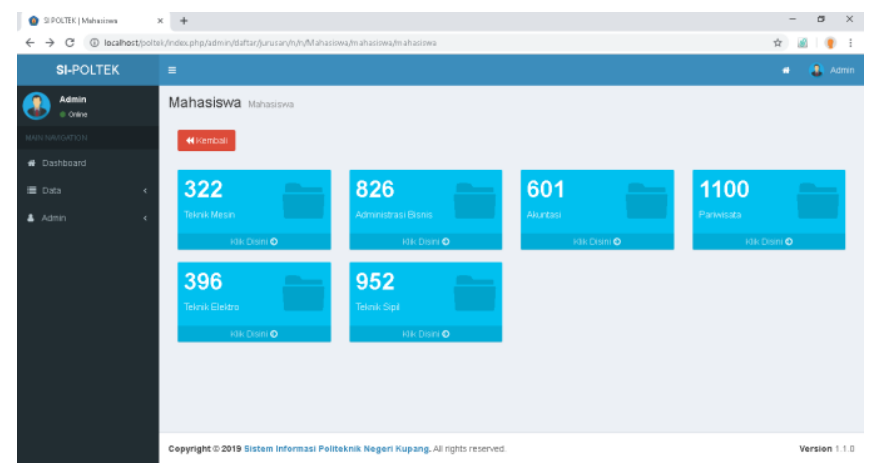

Figure 5. Dashboard students graduating Cum Laude

Figure 5 is an academic dashboard of study program performance based comparison or ratio of the number of students graduating cum laude with all graduates on study programs according to the year of graduation according to the Department. This dashboard report has function to inform the number of students graduating cum laude, the total number of graduatesat the Department, the ratio between graduating cum laude with the total number of graduates, performance indicators,performance predicate and decision recommendations in each department based on graduation year

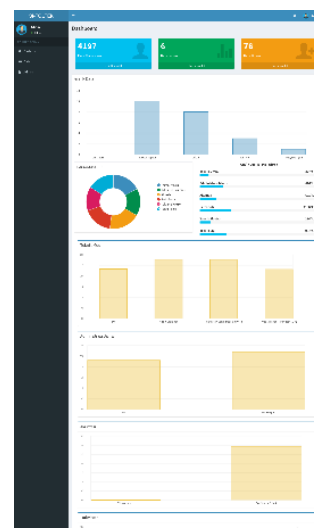

Figure 6. Dasboard Academic Management of Universities

Information that can be drawn from the data graph system dashboard is the associate professor and the assistant professor have superior opportunities in lecturer data, while student data in the form of GPA percentages from mechanical engineering, business administration, Accounting, Tourism, Electrical Engineering, Civil Engineering, can also be seen that electrical engineering still has the lowest GPA percentage of the accessible student data. Therefore, the leaders of the tertiary institutions can make the decision to immediately formulate a strategy for the department, as well as monitoring and evaluation materials for tertiary institutions. 


\section{Conclusions}

Business Intelligence is used as a solution to consider processesin decision making on academic management of universities and also solutions for improvement of academic management performance in achieving academic excellence, where the Business Intelligence system starts withdata integration stages, then make data analysis, then make analysis reports and create a web portal which then reports are integrated with the web portal. The plot of university Business Intelligence system processes include data source, data integration,data warehouse, data analysis and web portal. The University Business intelligence system web portal has information in the form of Department statistical reports, lecturer statistics, and student statistics and academic dashboards that can be used as analysis tools academics to support academic decision making at universities.

\section{Acknowledgements}

The authors would like to thank Politeknik Negeri Kupang for the financial support through the RUTIN Research program me.

\section{References}

[1] Turban, E., Aronson, E.J., Liang, T.P., Sharda, R., 2007. Decision Support and Business Intelligence Systems. Eight Edition, Pearson Education, Inc., New Jersey Edisi 7 Jilid 1, Penerbit ANDI, Yogyakarta.

[2] Sommerville, I., 2003. Software Engineering, Edisi 6, Jilid 1, Erlangga, Jakarta.

[3] Inmon, W.H., 2002. Building the Data Warehouse, Fourth Edition, Wiley Publishing Inc, Indianapolis.

[4] Kemper, H.G., Baars, H., 2006. Business Intelligence and Competitive Intelligence. HMD - Praxis der Wirtschaftsinformatik, 247, 7-20.

[5] Kimball, R., Caserta, J., 2004. The Data Warehouse ETL Toolkit, New Edition, Wiley Publishing Inc, Indianapolis.

[6] Davies, P., 2004. Database Systems Third Edition, Palgrave Macmillan, New York.

[7] Ponniah, P., 2001. Data Warehouse Fundamentals: a Comprehensive Guide for IT Professional, John Wiley and Sons Inc, New York.

[8] Santosa, B., 2007. Data Mining: Teknik Pemanfaatan Data untuk Keperluan Bisnis, Graha Ilmu, Yogyakarta.

[9] Brannon, N., 2010. Business Intelligence and E- Discovery, Intellectual Property \& Technology Law, Journal Vol. 22 July 2010.

[10] Parmenter, D., 2007. Key Performance Indicators, John Wiley and Sons Inc, New York. 